\title{
Technology vs Nature: Human Error in Dealing with Nature in Crichton's Jurassic Park
}

\author{
Liliek Soelistyo and Sarah Prasasti
}

\begin{abstract}
Witnessing the euphoria of the era of biotechnology in the late twentieth century, Crichton exposes the theme of biotechnology in his works. In Jurassic Park, he voices his concern about the impact of the use of biotechnology to preserve nature and its living creatures. He further describes how the purpose of preserving nature and the creatures has turned out to be destructive. This article discusses Crichton's main character, Hammond, who attempts to control nature by genetically recreating the extinct fossil animals. It seems that the attempt ignores his human limitations. Although he is confident that has been equipped with the technology, he forgets to get along with nature. His way of using technology to accomplish his purpose proves not to be in harmony with nature. As a consequence, nature fights back. And he is conquered.
\end{abstract}

Keywords: biotechnology, bioengineering, genetics, cloning, DNA, extinct fossil, pre-historic animal. Nature, human being

\section{Discovery is always a rape of the natural world (Crichton)}

Since the second half of the $20^{\text {th }}$ century, America has greatly surprised the world with their scientific invention. Well known as a nation with "a good climate" for science and technology (George,54), American scientists have consecutively conducted a series of spectacular and controversial experiments. Soon after the atomic and space ages, genetic research has revolutionized all aspects of life (www.newscientist.com/nsplus/insight/clone.html). Not surprisingly, scientists have come under the frequent and determined demands of the development of technology, especially biotechnology. Among the demands are the claims that biotechnology becomes the device in preserving creature and its nature. The heated debate about the concerns over animal genetic engineering forces people to sit down and have a good think about how the world might change. Whereas, then, the concern have extended, in our view, to the domain of literature.

Science fiction, as the energetic imitation of the scientific era, critically captures the initial euphoria of this newfound technology. Authors of science fiction play constantly with the themes of biotechnology in their literary works. They become mass-produced and simultaneously may become the agent of change of how to use technology to preserve nature. Responding to the growing concern of the application of biotechnology, Michael Crichton(1991), as one of the popular authors, perpetually responds to that phenomena. We are of the opinion that understanding Crichton's idea about biotechnology is very essential. Observing the astonishing progress of biotechnology, he puts forward three important respects in the genetic era. First, biotechnology is a "broad-based" project involving hundred corporations and thousand laboratories. Second, most research about it is considered "thoughtless" in the sense that nature is 
abused. The third is the fact that there is no law and government policy controlling the research. The most disturbing fact is, as Crichton emphasizes, the absence of a "watchdog" among the scientists (Cricthon vii). Clearly he voices his concern with human beings who tend to have a compelling urge, not only to pursue knowledge, but also to push the boundaries,or, to its extreme, even to break them (www.newscientist.com/nsplus/insight/clone.html).

Indeed, he has succeeded in promoting his concern through his novel, Jurassic Park, which has been proceeded by Hollywood film industry. He blends the factual element, spcecifically the current social phenomena, with the fictional ones by inventing a genetic engineering project with the prospects of cloning the extinct animal. Crichton depicts one representative character, John Hammond, a billionaire who attempts to deal with nature by engineering a genetic experiment in "recovering and cloning fossil animals." This article traces how Hammond tries to interfere and to control nature by means of technology and how he finally has to be conquered by nature.

Crichton's scientific concerns, in our view, have been reflected in Hammond's reconstruction of DNA to revert the fossil animals from extinction by "extracting DNA fragments from dinosaur bones (Crichton 67)." His ambition, in fact, corresponds with the scientists' effort nowadays in stepping forward to "chemically manipulate heritable characteristics" to produce "new form" of plants and animals (EA 771). Though it seems that his ambition is hardly accomplished, it is equipped by fund, which makes it possible to bring it into reality.

Crichton's careful analysis of the character of Hammond, an elderly billionaire of seventy-six, leads to several important points to remark. He possesses some inner qualities, which enable him to be the mastermind of this project. The comments from some experts around him illustrate a number of his characteristic features and complexity. Only after brief encounters with Hammond they quickly recognize him as an "eccentric dinosaur nut (Crichton 35)." Even, some of them have the impression that Hammond has a sort of "childlike quality," with "vision and enthusiasm (59)." In contrast with these childlike qualities, he is also considered as being "flamboyant". We detect the fact that right from the beginning, Hammond uses animals as a means of commercialization and social outing. Being "a born showman" (59), he proudly shows off a nine inch high and a foot long tiny elephant in fund-raising meetings. He ignores the fact that the process of miniaturization has changed the elephant's mental behavior. Interestingly paralleling to his being nut about science is his stubbornness. These character traits, if we may argue, signify the complexity of a man who donates billion dollars to carry out these ambitious bioengineering projects.

As has been pointed, without money Hammond's ambition will not engender this costly project. Money, in this case, becomes a very significant element. In any case, the power of money is everywhere present in $\underline{\mathrm{P}}$, and Hammond is powerless to control it which is not to say either that another, perhaps other experts could control it or that Hammond is the slave of money. We cite the example of Hammond being asked by Gennaro whether the park is ready for visitors to which he responds confidently that it is not officially open, though it is "to make money" (62). Without question, the money involves investment in terms of financing the project, and paying for all the expenses. As a person who has invested and done a lot for the project, Hammond believes that the project is not beyond control.

With his confidence, as the writers see, Hammond attempts to exercise the dominating influence over nature. Hammond and his experts are certain that with the power of biotechnology they have already had the recreated extinct animals in their 
hands. Undoubtedly, they are proudly celebrating what they have achieved while at the same time, without any awareness, they are challenging nature. Clarification of, as well as support for, our point that they hold on their celebration appears on their strategy in setting up the pre-historic park. Being extremely careful with any possibility that may happen, they have built, in our view, three layers of high technologyfortification. First is their intention to physically control the environment. The choice of a perfectly isolated and uninhabited Isla Nublar and their effort of building electrified fences and ditches around the perimeter of the land illustrate this purpose. In our opinion, this effort seems to be workable with the aid of the technology they have. The second protection is their attempt to control the population of the recreated pre-historic animals by creating only female animals and sterilizing them. Third, they try to imprison the animals. They unconsciously deny the law of nature by keeping different kinds of species from mingling with one another. In addition, the scientists even genetically engineer the animals to be unable to survive out of the island by making them "lysine dependent" (113). Playing god-like, they keep the animals as their "prisoners" (113) by taking care of them always on the track, counting as well as detecting their whereabouts every few minutes. With layers of designed safety system, they are sure that they hold all the cards to make the Jurassic park the most awesome "tourist attraction in the history of the world" (65). So far, they have been so preoccupied with their success to revive the extinct dinosaur.

To be specific, in our view, as a response to Hammond's "challenge", nature fights back. Unexpectedly, as far as human is concerned, Hammond is trapped in his human limitation by trespassing the boundary of nature. His three prepared fortifications fall uncontrollably one by one without mercy. The first layer, the electrified fences, which, if we may argue, symbolizes human beings' feeling of security, fails. The blackout of the electricity by the lightning signifies the force of nature toward human beings as shown by the fact that Hammond and his friends become powerless in totally isolated prehistoric jungle. The most fearful fact is that there are no bars between human beings and the animals. It seems that Hammond and his people cannot rely anymore on the technology they build. The limitation of human knowledge and the uncontrollable mighty nature break the second layer down. A remark from Ian Malcolm, one of Hammond's experts, clarifies our point that human knowledge is, indeed, limited. Malcolm, who we view as Cricthon's spokesperson, bitterly comments on the knowledge

They (scientists) don't have intelligence. They have what I call 'thintelligence". They see the immediate situation. They think narrowly and they call it 'being focused'. They don't see the surround. They don't see the consequences. That's how you get an island like this. From thintelligent thinking. (284)

The scientists are silenced by a too late awareness that all born female animals do breed with their natural ability to have a gender transition. The last fortification to totally control the animals' whereabouts finally fails. Their ways to protect the different kinds of species from freely mingling with each other turn out to be chaotic. The Jurassic Park, unexpectedly, naturally becomes the true Jurassic jungle. The worst is some prehistoric animals escape from the island and roam the mainland of Costa Rica. Once again Cricthon uses Malcolm to voice his concern: "Because you cannot make an animal and not expect it to act alive. To be unpredictable. To escape. But they don't see that" (284). Malcolm's argument is true, in our view, that the unpredictable nature has finally defeated Hammond. In our opinion the failure of the attempt to use technology on fulfilling his ambitious project signifies the fact that man-made 
technology cannot be confused with nature. Crichton's idea is particularly clear when he proceeds to analyze how human beings are insignificant in facing nature. The military operation of Costa Rica bombs the reconstructed prehistoric island, which finally turns to be a dangerous jungle of all mankind. In addition, the fact that some raptors escape from the explosion, migrating toward the mainland where human beings live shows that nature determines to strive back. Genetically the raptors are "lysine dependent" which are supposedly unable to live outside the island. Ironically, in our view, the raptors, proving themselves to be the survival of the fittest, survive by greedily eating crop rich in lysine. Thus, the fact raises the idea most forcefully that the laws of the jungle knock the biogenetics out. Perhaps Crichton's clearest account of the conflict between human beings and nature and their relationship occurs when death becomes the turning point of his character. Compys, recreated prehistoric animals as big as chickens, whose bites have a slow-acting poison, get Hammond (393). It seems very clear to us that Hammond's failure to reconciliate with nature indicates that he never regrets of what he has done. Even, when everything turns to be chaotic, he still stubbornly thinks "he would do better next time" (381).

His downfall can be traced earlier by the fact that Hammond has already had all of the needed components to make his scientific project a successful one: ambition, wealth, human resources and high technology. However, just like most scientists nowadays, he lacks one vital, but often forgotten component, that is the knowledge of human limitation that signifies a mature awareness of what to do and what not to do, as it is stated by Malcolm, "I want people to wake up. We've had four hundred years of modern science, and we ought to know by now what it's good for and what it's not good for" (285). This single fault triggers nerve cracking conflict between nature and Hammond and his people. Hammond's rejection to humbly respect the power of nature costs him his life.

To sum up, we are of the opinion that witnessing the "scientific gold rush" (ix), Cricthon, calls on the people to be more considerate of nature. He tries to convince people that any ambitious attempt to totally control nature is bound to fail. Malcolm's comment below, in our opinion, echoes Crichton's personal philosophy on the ideal interrelationships between nature and human beings.

When the hunter goes out in the rain forest to seek food for his family, does he expect to control nature? No. He imagines that nature is beyond him. Beyond his understanding. Beyond his control. Maybe he prays to nature, to the fertility of the forest that provides for him. He prays because he knows he doesn't control it. He is at the mercy of it (350).

The quotation we expose clarifies the idea that if human beings show their superiority by not being at the mercy of nature, or in other words refusing to admit that nature is bounderless, then at that moment, they will be in deep trouble. Through Hammond's failure, it seems that Crichton proves his assumption in the introduction of his $J P_{-}$that any effort to change nature by the use of advanced technology may seem like "a joke" (vii).

In addition to the conclusion we have drawn, on one point at least Crichton appears to be profoundly similar to any other literary authors, for he denies over and over again that any such interference with nature can be totally accepted. It is impossible to step outside the law of nature; the attempt to do so will necessarily be assaulted in the very terms the author aims to dislodge. Hammond and his people are the proofs. Crichton insists, therefore, in our opinion, that nature has neither defect nor imperfection, while man-made biotechnology remains imperfect. Not arguing about the importance of 
bioengineering, we are of the opinion that Crichton's JP is a piece of evidence that reveals the factual phenomena, that is the impetuous speed to commercialize genetic engineering in the late twentieth century.

\section{References}

Atkinson, G. Douglas. (1983). Reading deconstruction: Deconstructive reading. Kentucy: University Press of Kentucky.

Clark, George, Ed. A republic of science: Inquiry and innovation science and medicine. Portrait of the USA. United States Information Agency.

Considine, Douglas M. (1968). Van nostrand's scientific encyclopedia. D Van Nostrand Company, Inc.

Crichton, Michael. (1991). Jurassic park. Great Britain: Cox and Wyman Ltd.

Selden, Raman (1985). A reader's guide to contemporary literary theory. Lexington: UP of Kentucky.

Cloning-- www.newscientist.com/nsplus/insight/clone.html 